\title{
ANALISIS KESESUAIAN LAHAN WILAYAH PESISIR KOTA BENGKULU MELALUI PERANCANGAN MODEL SPASIAL DAN SISTEM INFORMASI GEOGRAFIS (SIG)
}

\author{
Yulian Fauzi *, Boko Susilo ** dan Zulfia Memi Mayasari * \\ *Dosen Fakultas MIPA Universitas Bengkulu \\ ${ }^{* *}$ Dosen Fakultas Teknik Universitas Bengkulu \\ E-mail: yulian.fauzi@yahoo.com
}

\begin{abstract}
This research is aimed to alocate land management and use coastal and ocean area Sub-Province base on digital through Geographical Information System (GIS). This research was done in the coastal area Kota Bengkulu, through spatial alocate analysis and land suitability analysis for brackish water fish ponds, maritime tourism and conservation areas. Approach used in this research is spatial analysis to parameter/variable and land suitability criteria consist of element abiotik, biotik, culture, and spatial use (RTRW). Land suitability analysis is done by using SIG through overlay technique. Result of research indicate that from 7 sub district of coastal area of exist in Kota Bengkulu, land suitability (S1) for brackish water fish ponds are found in sub-district Muara Bangkabulu and Kampung Melayu. Land suitability (S 1) for the maritime tourism are found in sub-district Teluk Segara and Ratu Samban, while Land suitability (S 1) for conservation area of are found in sub-district Kampung Melayu.
\end{abstract}

Keywords: coastal area, spatial model, land suitability, GIS

\section{PENDAHULUAN}

Pemanfaatan Sistem Informasi Geografis (SIG) menjanjikan pengelolaan sumber daya dan pembuatan model terutama model kuantitatif menjadi lebih mudah dan sederhana. SIG merupakan suatu cara yang efisien dan efektif untuk mengetahui karakteristik lahan suatu wilayah dan potensi pengenibangannya. Aplikasi SIG untuk pengelolaan wilayah pesisir dan laut telah banyak digunakan seperti penyusunan basis data wilayah pesisir dan evaluasi kesesuaian lahan pesisir (Fauzi, 2008; Islam, 2006, Tahir, 2002) monitoring dan manajemen shoreline (Li, 1998), dan perencanaan zone (Bhardwaj, 2002).
Salah satu kemampuan penting dari SIG adalah kemampuannya dalam melakukan analisis dan pemodelan spasial untuk menghasilkan informasi baru. Burrough dalam Danoedoro (1996) menjelaskan bahwa dalam SIG, entitas atau nilai atribut baru dapat diciptakan dari entitas yang telah ada beserta atributnya, baik yang bersifat eksak maupun tidak. Secara matematis, untuk sembarang lokasi nilai yang diturunkan dari suatu atribut dapat direpresentasikan dengan fungsi matematis sederhana seperti model USLE (Universal Soil Loss Equation). 
Kota Bengkulu merupakan salah satu wilayah administrasi yang mempunyai wilayah kecamatan pesisir yang cukup luas (Fauzi, 2006). Sumber daya wilayah pesisir di daerah ini pada umumnya belum dikelola clan dimanfaatkan secara optimal dan bahkan belum dilakukan inventarisasi secara sistematik dan berkelanjutan. Bahkan pemanfaatan lahan wilayah pesisir cenderung lebih berorientasi ke asas ekonominya dan kurang mempertimbangkan asas kelestarian dan daya dukung lahan (kesesuaian lahan). Menurut Harjadi (2004) agar pemanfaatan lahan dapat optimum perlu dilakukan evaluasi kesesuaian lahan.

Kesesuaian lahan (land suitability) merupakan kecocokan (adaptability) suatu lahan untuk tujuan penggunaan tertentu, melalui penentuan nilai (kelas) lahan serta pola tata guna lahan yang dihubungkan dengan potensi wilayahnya, sehingga dapat diusahakan penggunaan lahan yang lebih terarah berikut usaha pemeliharaan kelestariannya. Pengembangan daerah yang optimal dan berkelanjutan membutuhkan suatu pengelolaan keruangan wilayah pesisir yang matang. Berkaitan dengan hal tersebut, maks kajian tentang model pengelolaan dan arahan pemanfaatan wilayah pesisir yang berbasis digital dengan menggunakan SIG merupakan suatu hal yang sangat penting dan perlu dikaji lebih lanjut.

\section{METODE PENELITIAN}

\section{A. Wilayah Studi}

Kota Bengkulu secara geografis berada, antara 102'14'42" - 102 $22^{\circ} 45^{\prime \prime}$ Bujur Timur dan 343'49" - 401'00" Lintang Selatan dan terletak antara $3^{\circ} 45^{\prime \prime}-3^{\circ} 57$ dari Garis Equator atau 2048" sebelah Selatan Garis Khatulistiwa, dengan luas daratan 14.452 ha. Berdasarkan kriteria wilayah kecamatan yang memiliki ekosistem pesisir atau berbatasan langsung dengan perairan laut, maka di Kota Bengkulu. terdapat 7 Kecamatan pesisir dari 8 Kecamatan yang ada yaitu: Muara Bangkahulu, Sungai Serut, Teluk Segara, Ratu Agung, Ratu Samban, Gading Cempaka dan Kampung Melayu. Satu kecamatan yang tidak memiliki wilayah pesisir dan laut adalah Kecamatan Selebar.

\section{B. Pengumpulan Data}

Metode penelitian yang digunakan terdiri dari pengumpulan data, analisis spasial dan analisis lahan. Pengumpulan data yang dilakukan meliputi data vektor berupa peta rupa bumi dan peta tematik. Data vektor yang dikumpulkan dari instansi-instansi terkait (Bakosurtanal, Departemen Kehutanan dan Bappeda) meliputi peta lereng, peta jenis tanah, peta penggunaan lahan, peta administrasi, peta hutan lindung, peta ekosistem pesisir, peta pariwisata, peta utilitas dan peta, aksesbilitas. Pengumpulan data primer meliputi data sosial ekonomi dan data penggunaan lahan saat ini. Data yang telah dikumpulkan baik data primer maupun data sekunder sebelum, masuk kedalam tahap analisis akan diolah terlebih dahulu.

\section{Analisis Spasial}

Analisis spasial ini adalah membuat model prosedur analisis keruangan dengan memanfaatkan fasilitas SIG. Dalam penentuan kriteria dan parameter/variabel tersebut mengacu pada model-model sebelumnya telah dibuat oleh Purwadhi (2000), Widodo, dkk (1996), Bakosurtanal (1996), Kriteria, yang digunakan dalam analisis alokasi ruang ini adalah kriteria umum dan parameternya masih bersifat sementara. Analisis spasial menggunakan formula matematis sebagai berikut: 


$$
\begin{aligned}
\mathrm{P}(\mathrm{x})= & \mathrm{f}(\text { Abiotik })+\mathrm{f}(\text { Biotik })+ \\
& \mathrm{f}(\text { Sosek })+\mathrm{f}(\text { RTRW })
\end{aligned}
$$

di mana,

$$
\begin{aligned}
\mathrm{P}(\mathrm{x})= & \text { daerah potensial untuk } \\
& \text { pengembangan usaha } \mathrm{x} .
\end{aligned}
$$

\section{Analisis Kesesuaian Lahan}

Analisis lahan dimaksudkan untuk mengetahui kesesuaian lahan untuk pengunaan lahan tertentu. Dalam menentukan tingkat kesesuaian lahan ditentukan dengan metode pengharkatan dengan mengambil beberapa parameter serta pembobotan dalam menentukan tingkat kesesuaiannya.

Kesesuaian lahan untuk perikanan tambak yang berhasil dirancang melalui model matematis berikut:

$$
\begin{aligned}
\mathrm{PT}= & \mathrm{S}(\mathrm{E})+\mathrm{LR}(<3)+\mathrm{R}(<2000) \\
& +\mathrm{P}(<4000)+\mathrm{PL}(\mathrm{r}, \mathrm{b})+ \\
& \mathrm{MP}(\mathrm{n})+\mathrm{J}(<2000)+\mathrm{RTR} \\
& \mathrm{W}(\mathrm{B})
\end{aligned}
$$

Keterangan:

$$
\begin{aligned}
& P T=\text { Wilayah potensial untuk } \\
& \mathrm{S}=\text { Jenis tanah Entisol }(\mathrm{E}) \\
& L R=\text { Kelerengan datar }:(0-3 \%) \\
& \mathrm{R}=\text { Jarak dari sungai }(0-2000 \\
& \text { meter) } \\
& \mathrm{P}=\text { Jarak dari pantai }(0-4000 \\
& \text { meter) }
\end{aligned}
$$

Kesesuaian lahan pariwisata pesisir yang berhasil dirancang melalui model matematis berikut:

$$
\begin{aligned}
\mathrm{PP}= & \mathrm{P}(\mathrm{p})+\mathrm{J}(\mathrm{c})+\mathrm{B}(<5)+\mathrm{V}(\mathrm{k}, \\
& \mathrm{pp})+\mathrm{PL}(\mathrm{It})+\mathrm{MP}(\mathrm{n}, \mathrm{d})+\mathrm{J}(< \\
& 500)+\mathrm{S}(\mathrm{at}, \mathrm{h})+\mathrm{RTRW}(\mathrm{P})
\end{aligned}
$$

Keterangan :

$$
\begin{aligned}
P P= & \text { Wilayah potensial untuk } \\
& \text { pariwisata pesisir } \\
\mathrm{P}= & \text { Jenis pantai }: \text { berpasir }(\mathrm{p}) \\
\mathrm{i}= & \text { Kecerahan perairan }: \text { cerah } \\
\mathrm{B}= & \text { Kedalaman perairan }(0-5 \\
& \text { meter }) \\
V= & \text { Vegetasi }: \text { kelapa }(\mathrm{k}), \text { pines } \\
& \text { pantai }(\mathrm{pp}) \\
P L= & \begin{array}{l}
\text { Penggunaan lahan }: \text { Lahan } \\
\end{array} \\
& \text { Terbuka }(\mathrm{It}) \\
M P= & \text { Mata Pencaharian Penduduk } \\
& : \text { nelayan }(\mathrm{n}), \text { pedagang }(\mathrm{d}) \\
\mathrm{i}= & \text { Jarak dari jalan }(0-500 \\
\text { meter }) & \begin{array}{l}
\text { Sarana }: \text { Air tawar }(\mathrm{at}), \text { Hotel } \\
\text { (h) }
\end{array}
\end{aligned}
$$

RTRW = Rencana penggunaan lahan untuk : pariwisata $(\mathrm{P})$

Kesesuaian lahan kawasan konservasi yang berhasil dirancang melalui model matematis berikut:

$$
\begin{aligned}
\mathrm{PK}= & \mathrm{S}(\mathrm{E})+\mathrm{V}(\mathrm{p}, \mathrm{m})+\mathrm{PL}(\mathrm{h})+ \\
& \text { RTRW }(\mathrm{K})
\end{aligned}
$$

Keterangan :

$$
\begin{aligned}
P K= & \text { Wilayah potensial untuk } \\
& \text { kawasan Konservasi }
\end{aligned}
$$

Analisis kesesuaian lahan pesisir Kota Bengkulu untuk berbagai per- 
untukan, budidaya perikanan tambak, pariwisata bahari (renang dan rekreasi pantai) dan konservasi wilayah pesisir dilakukan dengan teknik yang sama. Pertama, penetapan persyaratan (parameter dan kriteria), pembobotan dan scoring. Untuk masing-masing peruntukkan, penetapan persyaratan tidak sama. Parameter yang menentukan diberikan bobot terbesar sedangkan kriteria, (batas-batas) yang sesuai diberikan skor tertinggi. Parameter, bobot dan skor sistem penilaian masingmasing kesesuaian lahan disajikan dalam bentuk matriks kesesuaian lahan (lampiran 1). Kedua perhitungan nilai peruntukkan lain. Penghitungan kesesuaian dilakukan dengan mengalikan bobot dengan skor, untuk sesuai (skor 3), sesuai bersyarat (skor 2) dan tidak sesuai (skor 1). Ketiga, pembagian kelas lahan. Berdasarkan perkalian bobot dan skor tersebut pembagian kelas lahan dan nilainya dalam penelitian ini dibagi dalam tiga kelas yaitu Kelas S1: Sesuai; Kelas S2 : Sesuai Bersyarat dan Kelas N: Tidak Sesuai.

Klasifikasi tingkat kesesuaian lahan berdasarkan jumlah perkalian bobot dan skor, kesesuaian lahan untuk budidaya, perikanan tambak, wisata bahari dan kawasan konservasi ditunjukkan dalam Tabel 1.
Keempat, memadankan (membandingkan) nilai lahan dengan nilai masing-masing kelas lahan. Kelima, penyajian grafis (spasial) hasil analisis berupa peta kesesuian lahan.

\section{HASIL DAN PEMBAHASAN}

Kota Bengkulu sebagai ibukota Provinsi Bengkulu dari waktu ke waktu terus mengalami pertumbuhan. Pertumbuhan tersebut dapat dilihat dengan terjadinya perubahan penggunaan lahan baik dari lahan tidur menjadi kawasan terbangun, maupun perubahan fungsi dari kawasan permukiman menjadi kawasan perdagangan. Kota Bengkulu terletak di Pantai Barat Sumatera yang berhadapan langsung dengan Samudera Hindia.

Lahan yang digunakan di Kota Bengkulu adalah lahan perairan dan daratan. Berdasarkan RTRW Kota Bengkulu tahun 2002 konsep pengembangan pemanfaatan ruang di Kecamatan Pesisir Kota Bengkulu terdiri atas: kawasan lindung/konservasi, pariwisata, perdagangan, industri, pergudangan dan permukiman. Berdasarkan observasi lapangan pengembangan pemanfaatan ruang di daerah pesisir Kota Bengkulu telah banyak yang beralih fungsi, seperti yang

Tabel 1. Klasifikasi Tingkat Kesesuaian Lahan Berdasarkan Total Bobot x Skor

\begin{tabular}{|c|c|c|c|}
\hline \multicolumn{3}{|c|}{ Total Skor pada } & \multirow{2}{*}{$\begin{array}{c}\text { Tingkat } \\
\text { Kesesuaian Lahan }\end{array}$} \\
\hline $\begin{array}{c}\text { Budidaya } \\
\text { Perikanan Tambak }\end{array}$ & Pariwisata Bahari & $\begin{array}{c}\text { Kawasan } \\
\text { Konservasi }\end{array}$ & \\
\hline $120-180$ & $100-150$ & $68-102$ & Sesuai \\
\hline $60-120$ & $50-100$ & $34-68$ & Sesuai bersyarat \\
\hline$<60$ & $<50$ & $<34$ & Tidak sesuai \\
\hline
\end{tabular}

Sumber: Hasil Analisis 
terjadi di Kecamatan Kampung Melayu. Kawasan ini awalnya berupa rawa-rawa, tetapi saat ini telah beralih fungsi menjadi perkebunan kelapa sawit, permukiman dan perkebunan palawija.

Penggunaan lahan diwilayah pesisir Kota Bengkulu yang dimanfaatkan untuk wisata terdapat di pantai Panjang yang meliputi wilayah administrasi Kecamatan Teluk Segara dan Kecamatan Ratu Samban. Di daerah ini juga berkembang kawasan perhotelan dan pusat perbelanjaan Bengkulu Indah Mall. Perkembangan kawasan ini dipacu dengan tingginya kunjungan wisatawan domestik yang sering terjadi pada hari-hari libur. Penggunaan lahan berupa hutan pantai dan hutan konservasi di kawasan ini masih tetap dipertahankan. Hutan pinus tersebar sepanjang pantai panjang ujung (pasir putih) sampai kelurahan Sumur Meleleh, sedangkan kawasan konservasi terdapat mulai dari muara sungai Jenggalu sampai ke alur Pulau Bai.

Penggunaan lahan untuk wisata pada dua tahun ini berkembang clan terkonsentrasi di Pantai Zakat. Wisata yang dikembangkan di daerah ini berupa wisata bahari berupa kegiatan renang. Perkembangan daerah ini terpacu sejak dibangunnya sarana jalan dari Tapak Paderi sampai ke Terminal Sungai Hitam. Rekreasi renang di pantai ini didukung juga oleh bentuk pantai yang berupa teluk, sehingga gelombang laut tidak terlalu tinggi.

\section{A. Kesesuaian Lahan Budidaya Per- ikanan Tambak}

Pada prinsipnya lahan yang akan digunakan untuk budidaya perikanan tambak harus memenuhi persyaratan fisika, kimia, biologis, teknis, sosial ekonomi, higienis dan legal. Guna mendapatkan lahan yang memenuhi persyaratan tersebut, ada 4 aspek utama yang perlu diperhatikan sebagai kriteria dalam penentuan lokasi tambak yaitu aspek ekologis, aspek tanah, aspek biologis dan aspek sosial. Keempat aspek tersebut menjadi unsur pendukung pengembangan usaha perikanan tambak di pesisir Kota Bengkulu dan hal tersebut dijadikan sebagai dasar penilaian dalam merancang model kesesuaian lahan.

\section{B. Kesesuaian Lahan Pariwisata Bahari}

Alokasi spasial untuk kesesuaian lahan pariwisata dilakukan melalui analisa beberapa faktor yang memengaruhi kesesimian lahan, faktorfaktor yang dapat dianalisa adalah 1) Keterlindungan perairan, faktor ini memperhatikan keberadaan terumbu karang sebagai pelindung dan pemecah ombak di perairan wilayah pesisir, daerah teluk dan perairan yang terlindung pulau yang besar ombak dan arusnya relatif rendah dan tenang. 2) Wilayah konservasi atau Jalur hijau pantai, faktor ini memperhatikan keberadaan hutan mangrove dan sumberdaya alam pesisir lainnya yang perlu dilestarikan. 3) Masalah pencemaran, 4) Aksesbilitas faktor ini memperhatikan sarana/prasarana, jaringan jalan dan bentuk pantai. Berdasarkan faktor-faktor yang harus dianalisis tersebut variabel yang dijadikan dasar dalam merancang model spasial untuk pengembangan usaha pariwisata bahari (renang dan rekreasi pantai) di Kota Bengkulu.

\section{Kesesuaian Lahan Kawasan Konservasi}

Konservasi wilayah pesisir adalah upaya perlindungan, pelestarian, dan pemanfaatan wilayah pesisir dan pulau-pulau kecil serta ekosistemnya, untuk menjamin keberadaan, keter- 
sediaan, dan kesinambungan sumber daya pesisir dengan tetap memelihara dan meningkatkan kualitas nilai dan keanekaragamannya (Permen DKP, 2008).

Kawasan konservasi adalah bagian wilayah pesisir yang mempunyai ciri khas tertentu sebagai satu kesatuan ekosistem yang dilindungi, dilestarikan dan/atau dimanfaatkan secara berkelanjutan untuk mewujudkan pengelolaan wilayah pesisir.

\section{Analisis Kesesuaian Lahan}

Hasil analisis spasial untuk kesesuaian lahan budidaya perikanan tambak dapat dilihat dalam peta kesesuaian lahan Gambar 1. Berdasarkan hasil analisis kesesuaian lahan diperoleh tiga kelas kesesuaian lahan di wilayah Pesisir Kota Bengkulu. Dari hasil teknik overlay didapatkan kecamatan-kecamatan pesisir yang memiliki potensi untuk pemanfaatan lahan budidaya perikanan tambak. Pertama adalah Kelas Sesuai (S1). Kelas memiliki nilai kesesuaian lahan yang berkisar antara $67-100 \%$, lahan ini tersebar di kecamatan Muara Bangkahulu (Kelurahan Rawa Makmur) dekat dengan sungai Air Bengkulu, Kampung Melayu tepatnya di sekitar kelurahan Padang Serai dekat dengan sungai Air Limau dan di Kecamatan Ratu Samban (Kelurahan Lempuing) dekat dengan sungai Air Jenggalu. Kedua adalah kelas Sesuai Bersyarat (S2). Lahan ini memiliki nilai kesesuaian antara 33 - $66 \%$ terdapat di sebagaian besar Kecamatan Muara Bangkahulu, Teluk Segara dan Kecamatan Ratu Agung. Ketiga adalah Kelas Tidak Sesuai (N). Kelas ini terdapat di kecamatan Sebagian besar Kecamatan Kampung Melayu, Selebar dan Gading Cempaka.
Hasil analisis spasial untuk kesesuaian lahan pariwisata bahari dapat dilihat dalam peta kesesuaian lahan Gambar 2. Berdasarkan hasil analisis kesesuaian lahan diperoleh tiga kelas kesesuaian lahan di wilayah Pesisir Kota Bengkulu. Berdasarkan hasil teknik overlay didapatkan kecamatan-kecamatan pesisir yang memiliki potensi untuk pemanfaatan lahan sebagai pariwisata bahari. Pertama adalah Kelas Sesuai (S1). Kelas memiliki nilai kesesuaian lahan yang berkisar antara $67-100 \%$, lahan ini tersebar di sebagian kecil Kecamatan Muara Bangkahulu tepatnya di daerah Muara Sungai Air Hitam, Kecamatan Teluk Segara, Kecamatan Ratu Agung dan Kecamatan Ratu Samban. Lokasi Pariwisata di kawasan Pantai Panjang memang sangat cocok dijadikan sebagai tempat rekreasi pantai tetapi tidak cocok untuk dijadikan sebagai wisata renang, hal ini dikarenakan kontur kedalaman pantai panjang berkisar antara 5 - 10 meter dengan ombak yang sangat tinggi. Lokasi yang cocok dijadikan sebagai wisata renang adalah di lokasi pantai Zakat, secara fisik daerah ini merupakan daerah teluk, dengan kontur kedalaman pantai antara 0- 5 meter.

Kedua adalah kelas Sesuai Bersyarat (S2). Lahan ini memiliki nilai kesesuaian antara $33-66 \%$ terdapat di sebagaian besar kecamatan Gading Cempaka dan Selebar. Berdasarkan hasil analisis daerah ini tidak bisa di kategorikan lagi sebagai wisata bahari, karena kedua kecamatan bukan dikategorikan sebagai kecamatan pesisir. Ketiga adalah Kelas Tidak Sesuai (N). Kelas ini terdapat di kecamatan Sebagian besar Kecamatan Kampung Melayu, hal ini dikarenakan 
kecamatan ini belum memiliki aksesbilitas dan sarana pariwisata bahari, hal ini juga didukung dengan RTRW Kota Bengkulu, bahwa keeamatan ini akan dijadikan sebagai kawasan industri.

Hasil analisis spasial untuk kesesuaian lahan kawasan konservasi dapat dilihat dalam peta kesesuaian lahan Gambar 3.

Berdasarkan hasil analisis kesesuaian lahan diperoleh tiga kelas kesesuaian lahan di wilayah Pesisir Kota Bengkulu. Pertama. adalah Kelas Sesuai (S1). Kelas memiliki nilai kesesuaian lahan yang berkisar antara $67-100 \%$, lahan ini tersebar di sebagian besar pesisir Kecamatan Kampung Melayu. Kecamatan ini merupakan daerah yang cocok untuk kawasan konservasi khususnya pada sempadan sungai Air Jenggalu sampai ke Alur Pelabuhan Pulau Bai. Hasil survey lapangan menunjukkan vegetasi di kawasan ini masih sangat lebat yang didominasi oleh pinus dan sebagian kecil mangrove. Tingkat kesesuaian lahan ini juga didukung oleh kebijakan pemerintah Kota Bengkulu dalam RTRW untuk menjadikan lokasi ini sebagai kawasan lindung. Kedua adalah kelas Sesuai Bersyarat (S2). Lahan ini memiliki nilai kesesuaian antara $33-66 \%$ terdapat di sebagian besar pesisir yang terdapat di Kecamatan Teluk Segara, Ratu Agung dan Ratu Samban. Ketiga adalah Kelas Tidak Sesuai (N). Kelas

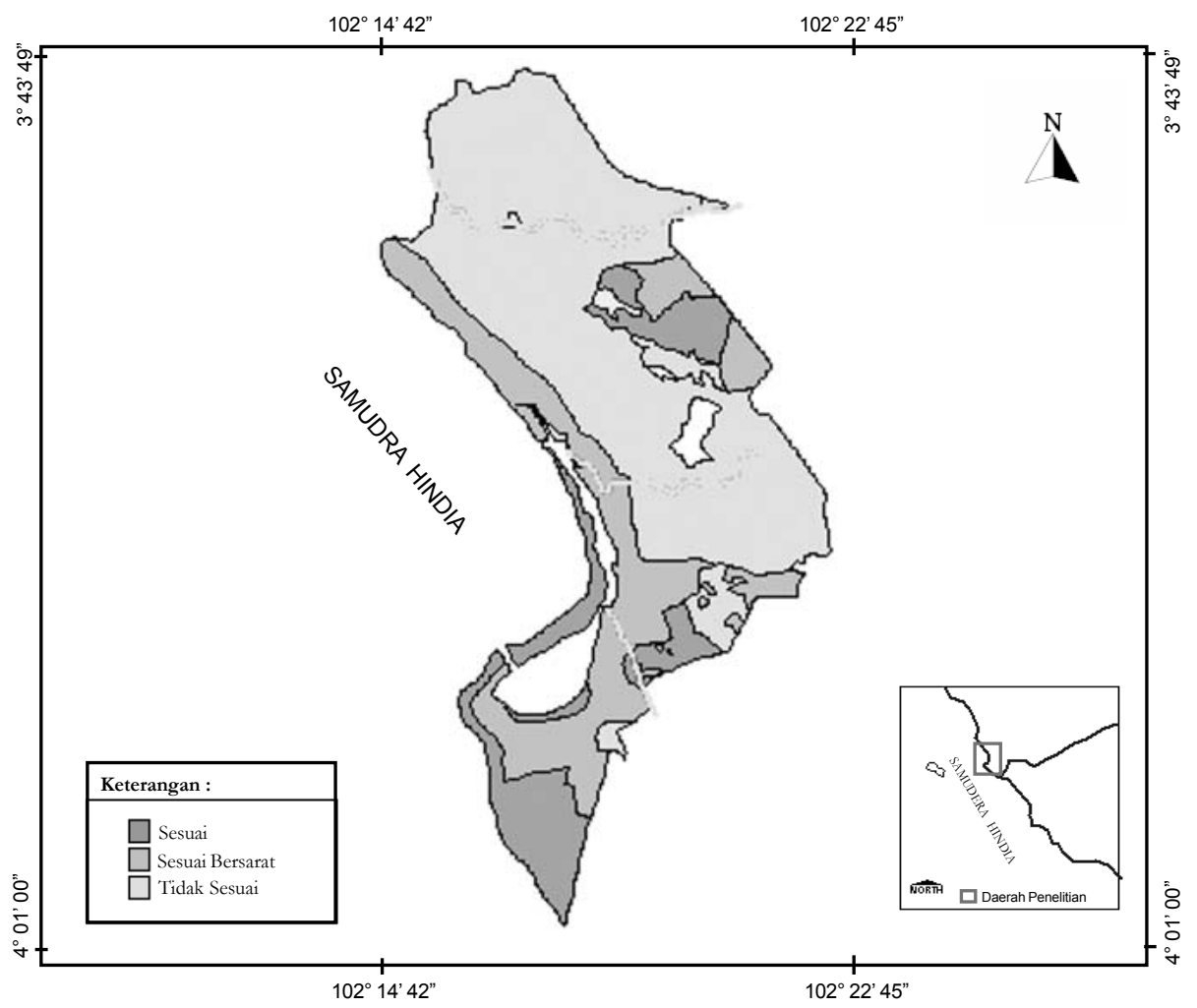

Sumber: Hasil Analisis

Gambar 3. Peta Kesesuaian Lahan untuk Kawasan Konservasi 
ini terdapat di kecamatan sebagian besar Kecamatan Muara Bangkahulu, Selebar, dan Gading Cempaka.

\section{KESIMPULAN}

1. Analisis spasial kesesuaian lahan yang berhasil dirancang dalam penelitian ini terdiri dari alokasi spasial kesesuaian lahan untuk budidaya perikanan tambak, pariwisata bahari (renang dan rekreasi pantai) dan kawasan konservasi di wilayah pesisir Kota Bengkulu, yang selanjutnya di presentasikan dalam bentuk matriks kesesuaian lahan dan peta kesesuaian lahan.

2. Kesesuaian lahan di wilayah pesisir Kota Bengkulu untuk budidaya perikanan tambak terdapat pada Kecamatan Muara Bangkahulu (Kelurahan Rawa Makmur) dan Kecamatan Kampung Melayu
(Kelurahan Padang Serai). Kesesuaian lahan untuk pariwisata pesisir (renang dan rekreasi pantai) terdapat di Kecamatan Teluk Segara dan Kecamatan Ratu Samban yaitu di kawasan wisata pantai Zakat, dan kawasan wisata alam Pantai Panjang. Kesesuaian lahan untuk kawasan konservasi terdapat di Kecamatan Kampung Melayu yaitu di Kelurahan Kandang (Sempadan Sungai Air Jenggalu) dan Alur Pulau Bai.

\section{UCAPAN TERIMA KASIH}

Ucapan terimakasih disampaikan kepada Dirjen Dikti melalui Direktorat Penelitian dan Pengabdian Masyarakat (DP2M) yang telah mendanai penelitian melalui penelitian Hibah Bersaing tahun 2009.

\section{DAFTAR PUSTAKA}

2008, Peraturan Menteri Kelautan Dan Perikanan Republik Indonesia Nomor Per.17/Men/2008 Tentang Kawasan Konservasi Di Wilayah Pesisir Dan Pulau-Pulau Keeil. Jakarta

Bakosurtanal. 2001. Laporan Akhir, Penyusunan Basisdata Tematik. Sumberdaya Alam. Kedasama Proyek MV-SNMI, - Bakosurtanal. Bogor.

Bappeda Kota Bengkulu. 2004. Renstra Wilayah Pesisir dan Laut Kota Bengkulu. Bengkulu

Bhardwaj. 2007. Application of GIS technology for Coastal Zone Management: a hydrografer perspective, diambil dari www.gisdevelopment.net/application_tanggal 3 maret 2007

Danoedoro. P.. 1996. Pengolahan Citra Digital. Teori dan Aplikasinya dalam Bidang Penginderaan Jauh. Fakultas Geografi. UGM. Yogyakarta

Fauzi, Yulian. 2006. Perancangan Sistem Basis data Spasial Wilayah Pesisir Kota Bengkulu Menggunakan Sistem Informasi Geografis (SIG). Laporan Penelitian Dana DIPA Universitas, Bengkulu tahun 2006. Bengkulu. (tidak dipublikasikan) 
Fauzi, Y., Susilo. B., dan Mayasari. Z.M., 2008, Model Pengelolaan Wilayah Pesisir Kota Bengkulu Menggunakan SIG. Makalah seminar nasional Semirata Bidang MIPA tahun 2008, Unsyiah. Banda Aceh.

Harjadi, B.. 2004. Karakteristik Sumberdaya Lahan Sebagai Dasar Pengelolaan DAS di Sub DAS Merawu, DAS Serayu. Forum Geografi. Vol. 18(2) Desember 2004: 98.

Islam. R.M.. 2006. Managing Diverse Land Uses in Coastal Bangladesh: Institutional Approachs. Diambil dari ,www.iwni.cgiar.org/publication.pdf_tanggal 5 November 2009

Li, Rongxing. CW, Ramcharan. E, Kjerfve. B, and Willis, D. 1998, A Coastal GIS for Shoreline Monitoring and Management - Case Study in Malaysia, Surveying and land Information System, Vol. 58 (3): 157-166.

Purwadhi. 2000. Konsep Dasar Inderaja dan SIG untuk Studi Kesesuaian Lahan, Model Pelatihan Penginderaan Jauh dan SIG, LAPAN, Jakarta

Tahir, A, Bengen. D, and Susilo. S.B. 2002. Analisis Kesesuaian Lahan Dan Kebijakan Pemanfaatan Ruang Kawasan Pesisir Teluk Balikpapan, Jurnal Pesisir \& Lautan. Vol. 4 (3): 1-16. 


\section{LAMPIRAN 1}

Tabel 2. Matriks Kesesuaian Lahan Budidaya Perikanan Tambak

\begin{tabular}{|c|c|c|c|c|c|c|c|c|}
\hline \multirow[b]{2}{*}{ No. } & \multirow[b]{2}{*}{ Parameter } & \multirow[b]{2}{*}{ Bobot } & \multicolumn{6}{|c|}{ Tingkat Kesesuaian } \\
\hline & & & Sesuai & Skor & $\begin{array}{c}\text { Sesuai } \\
\text { Bersyarat }\end{array}$ & Skor & Tidak Sesuai & Skor \\
\hline \multirow[t]{5}{*}{1 . } & Abiotik & & & & & & & \\
\hline & - Lereng & 10 & $0-2 \%$ & 3 & $2-15 \%$ & 2 & $<15 \%$ & 1 \\
\hline & - Tanah & 8 & Entisol & 3 & Entiso1 & 2 & Non entisol & 1 \\
\hline & $\begin{array}{l}\text { - Hidrologi (jarak dari } \\
\text { sungai) }\end{array}$ & 8 & $0.500 \mathrm{~m}$ & 3 & $500.2000 \mathrm{~m}$ & 2 & $>2000 \mathrm{~m}$ & 1 \\
\hline & $\begin{array}{l}\text { - Pantai (jarak dari } \\
\text { pantai) }\end{array}$ & 8 & $0-2000 \mathrm{~m}$ & 3 & $2000-4000 \mathrm{~m}$ & 2 & $>4000 \mathrm{~m}$ & 1 \\
\hline 2. & Biotik & & & & & & & \\
\hline \multirow[t]{4}{*}{3.} & Sosek & & & & & & & \\
\hline & - Penggunaan lahan & 6 & $\begin{array}{l}\text { Hutan, rawa, } \\
\text { tegalan, belukar }\end{array}$ & 3 & $\begin{array}{l}\text { Sawah, } \\
\text { perkebunan }\end{array}$ & 2 & $\begin{array}{l}\text { Konservasi, } \\
\text { m angrove, } \\
\text { permukiman, } \\
\text { industri }\end{array}$ & 1 \\
\hline & $\begin{array}{l}\text { - Mata pencaharian } \\
\text { penduduk }\end{array}$ & 4 & Nelayan & 3 & Pedagang & 2 & PNS, swasta & 1 \\
\hline & - Aksesbilitas & 6 & $<1000 \mathrm{~m}$ & 3 & $1000-2000 \mathrm{~m}$ & 2 & $>2000 \mathrm{~m}$ & 1 \\
\hline \multirow[t]{2}{*}{4.} & Kebijakan Pemerintah & & & & & & & \\
\hline & - RTRW & 10 & Budidaya & 3 & Non budidaya & 2 & Non budidaya & 1 \\
\hline
\end{tabular}

Sumber: Purwadhi (2000), Widodo (1997) dengan modifikasi

Tabel 3. Matriks Kesesuaian Lahan Pariwisata Bahari (Renang dan Rekreasi Pantai)

\begin{tabular}{|c|c|c|c|c|c|c|c|c|}
\hline \multirow[b]{2}{*}{ No. } & \multirow[b]{2}{*}{ Parameter } & \multirow[b]{2}{*}{ B obot } & \multicolumn{6}{|c|}{ T ingkat Kesesuaian } \\
\hline & & & Sesuai & Skor & $\begin{array}{c}\text { Sesuai } \\
\text { Bersyarat }\end{array}$ & Skor & Tidak Sesuai & Skor \\
\hline \multirow[t]{4}{*}{1.} & Abiotik & & & & & & & \\
\hline & - Kontur kedalam an & 10 & Landai $(0-5 \mathrm{~m})$ & 3 & Landai $(5-10 \mathrm{~m})$ & 2 & Curam $(>10 \mathrm{~m})$ & 1 \\
\hline & - Kecerahan perairan & 6 & Cerah & 3 & Kurang cerah & 2 & Tidak cerah & 1 \\
\hline & - Jenis pantai & 6 & Berpasir & 3 & Tidak berpasir & 2 & Tidak berpasir & 1 \\
\hline \multirow[t]{2}{*}{2.} & Biotik & & & & & & & \\
\hline & - Vegetasi & 6 & Kelapa, sem ak & & Belukar tinggi & & Mangrove & \\
\hline \multirow[t]{5}{*}{3.} & Sosek & & & & & & & \\
\hline & - Penggunaan lahan & & Lahan terbuka & 3 & Lahan terbuka & 2 & $\begin{array}{l}\text { Perm ukim an, } \\
\text { pelabuhan }\end{array}$ & 1 \\
\hline & $\begin{array}{l}\text { - Mata pencaharian } \\
\text { penduduk }\end{array}$ & 4 & $\begin{array}{l}\text { Nelayan, } \\
\text { pedagang }\end{array}$ & 3 & Nelayan & 2 & PNS, swasta & 1 \\
\hline & - Aksesbilitas & 4 & & 3 & & 2 & & 1 \\
\hline & - Sarana & 4 & $\begin{array}{l}\text { Tersedia air } \\
\text { tawar, hotel }\end{array}$ & & $\begin{array}{l}\text { Tidak tersedia } \\
\text { air ta war, hotel }\end{array}$ & & $\begin{array}{l}\text { Tidak tersedia air } \\
\text { tawar, hotel }\end{array}$ & \\
\hline \multirow[t]{2}{*}{4.} & Kebijakan Pemerintah & & & & & & & \\
\hline & - RTRW & 10 & Pariwisata & 3 & $\mathrm{~N}$ on pariw isata & 2 & Non pariwisata & 1 \\
\hline
\end{tabular}

Sumber: Bakosurtanal (1996) dengan modifikasi

Tabel 4. Matriks Kesesuaian Lahan Kawasan Konservasi

\begin{tabular}{|c|c|c|c|c|c|c|c|c|}
\hline \multirow{2}{*}{ No. } & \multirow{2}{*}{ Panmeter } & \multirow{2}{*}{ Bobot } & \multicolumn{6}{|c|}{ T'Tingkat Kesesuaian } \\
\hline & & & Sesuai & Skor & Sesuai Bes yamt & Skor & Tidak Sesuai & Skor \\
\hline \multirow[t]{2}{*}{1.} & Abiotik & & & & & & & \\
\hline & - Tanah & 6 & Entisol & 3 & Extisol & 2 & Non Entisol & 1 \\
\hline \multirow[t]{2}{*}{2.} & Biotik & & & & & & & \\
\hline & - Vegetasi & 10 & Mangrove & & Pinus & & Kelapa & \\
\hline \multirow[t]{2}{*}{3.} & Sosek & & & & & & & \\
\hline & - Pengugunaan lahan & 8 & Cagar alam & 3 & $\begin{array}{l}\text { Hutan parttai, } \\
\text { taman wrisata alam }\end{array}$ & 2 & $\begin{array}{l}\text { Permukiman, } \\
\text { pelabuhan }\end{array}$ & 1 \\
\hline \multirow[t]{2}{*}{4.} & Kebijakan Pemenintah & & & & & & & \\
\hline & - RTRW & 10 & Konservasi & 3 & Non Konservasi & 2 & Non Konservasi & 1 \\
\hline
\end{tabular}

Sumber: Puspic (1999) dengan modifikasi 